\title{
Preface - Creativity and HCI: From Experience to Design in Education
}

\author{
Paula Kotzé, William Wong, Joaquim Jorge, Alan Dix and Paula Alexandra \\ Silva \\ ${ }^{1}$ Meraka Institute, Centre for Scientific and Industrial Research, \\ and School of Computing, University of South Africa, \\ P O Box 395, Pretoria, 0001, South Africa \\ Paula.Kotze@meraka.org.za \\ WWW home page: http://www.meraka.org.za \\ Interaction Design Centre \\ ${ }^{2}$ School of Computing Science, Middlesex University, The Burroughs, \\ Hendon, London NW4 4BT UK. \\ w.wong@mdx.ac.uk \\ WWW home page: http://www.cs.mdx.ac.uk/research/idc \\ ${ }^{3}$ Department of Computer Science and Engineering, \\ Instituto Superior Técnico, \\ Technical University of Lisboa, Av. Rovisco Pais s/n, \\ Lisboa 1049-001, Portugal \\ jorgej@ist.utl.pt \\ WWW home page: http://web.ist.utl.pt/jorgej \\ ${ }^{4}$ Computing Department, InfoLab21, South Drive Lancaster University, \\ Lancaster, LA1 4WA, UK \\ alan@hcibook.com \\ WWW home page: http://www.hcibook.com/alan/ \\ ${ }^{5}$ Departamento de Matemática e Engenharias, Universidade da Madeira \\ Campus Universitário da Penteada, 9000-390 Funchal, Portugal \\ palexa@gmail.com \\ WWW home page: \\ http://dme.uma.pt/pt/people/faculty/Paula.Alexandra.Silva.html
}

\section{Introduction}

There was a time when we knew what to teach in our HCI courses ... For the early stages, we had user-centred design, perhaps ethnography or participatory design. As we looked in more detail there were interface guidelines and platform toolkits. Then, to evaluate we had heuristics (only five users needed, good for student groups), cognitive walkthroughs and formal experiments. Above all, we all knew our ISO

Please use the following format when citing this chapter:

Kotzé, P., Wong, W., Jorge, J., Dix, A. and Silva, P.A., 2009, in IFIP International Federation for Information Processing, Volume 289; Creativity and HCI: From Experience to Design in Education; Paula Kotzé, William Wong, Joaquim Jorge, Alan Dix, Paula Alexandra Silva; (Boston: Springer), pp. 1-11. 
mantra efficiency and effectiveness... and what was that third one? Of course some students still found it hard to 'think user', and it was such a pain trying to mark all that project-based coursework ... But we knew what we were doing, and we knew what we were designing for ... Computer systems stayed safely behind glass screens and about their only physical influence was when they spat out a floppy disk ...

But for several years now feral computers have escaped office desks, and found their way into bedrooms and television sets, mobile phones and smart cards ... They even talk to us in our cars and turn on the tap in the bathroom. Users have now even discovered that third part of the ISO mantra, but having done so are never satisfied and expect to enjoy using these things and even have fun! Even the safe world behind the glass screen has gone wild, with Web2.0, and community content ... Would the person who user-tested that JavaScript rollover, please stand up?

Of course, we can teach our students about AJAX and mobile usability guidelines, and on our reading lists Nielsen [1] is silently being dropped in favour of Csikszentmihalyi [2]. If we are especially adventurous we may even swap the odd lecture with a product designer. As for our students, when they hit the workplace they might manage a whole three or four years before the next wave of technology hits them, and they find themselves moving rapidly into management and seeking to recruit a fresh group of graduates who might just understand the latest acronym technology and interface fad.

If we are to equip our students for their future working lives we need to give them not merely the knowledge of current technology and practice, but the means to adapt and engage with whatever comes their way. They will clearly need fundamental understanding of people both cognitively and socially and to be able to learn new technologies as they emerge. However, they also need to apply these basic understandings to create innovative solutions to as yet unthought-of problems.

This volume comprises papers selected and developed from HCIEd 2007, the Second International Working Conference of Human-Computer Interaction Educators. All the papers in the volume has been subjected to two rounds of strict peer-review, and the final selection of papers in this volume reflects the best work presented and developed from the lesson learnt at HCIEd 2007.

The HCIEd series of conferences started off as a series of workshops run by the British Computer Society's Human-Computer Interaction (BCS HCI) Specialist Group's Education and Practice Sub-Group. For a number of years it had focused on revising the HCI syllabus in response to the changing technology environment, characterised by, for example, mobile computing, ubiquitous technology and an aging population. In parallel with this, Working Group (WG) 13.1 on Education in $\mathrm{HCI}$ and HCI Curricula of the International Federation for Information Processing (IFIP), with whom the BCS HCI Group is affiliated through Technical Committee (TC) 13, was running a series of workshops, mainly in Europe, focussing on HCI curricula and ways and means to teach HCI in order to 'experience HCI'. While curricula and syllabus issues are still on both groups' agendas, learning to create, learning to find innovative solutions and designs, so that we can further influence and make a significant impact on society, is becoming an increasingly important focus. In 2006 these two groups combined forces by deciding to jointly take these workshops to an international level, expanding the horizons and thinking about the teaching and learning of creativity and invention in HCI. The result of this 
cooperation was HCIEd 2006 in Limerick, Ireland, co-organised with the additional support of the EU CONVIVIO European Network for Human-Centered Design of Interactive Technologies. The paper by Wong et al. [3] in this volume describes the lessons learnt from HCIEd 2006 and serves as historical introduction to the rest of the papers in the volume. HCIEd 2007 was held in Aveiro, Portugal during March 2007, with the additional support of EPCG (Eurographics Portuguese Chapter) and IEETA (Instituto de Engenharia Electrónica e Telemática de Aveiro).

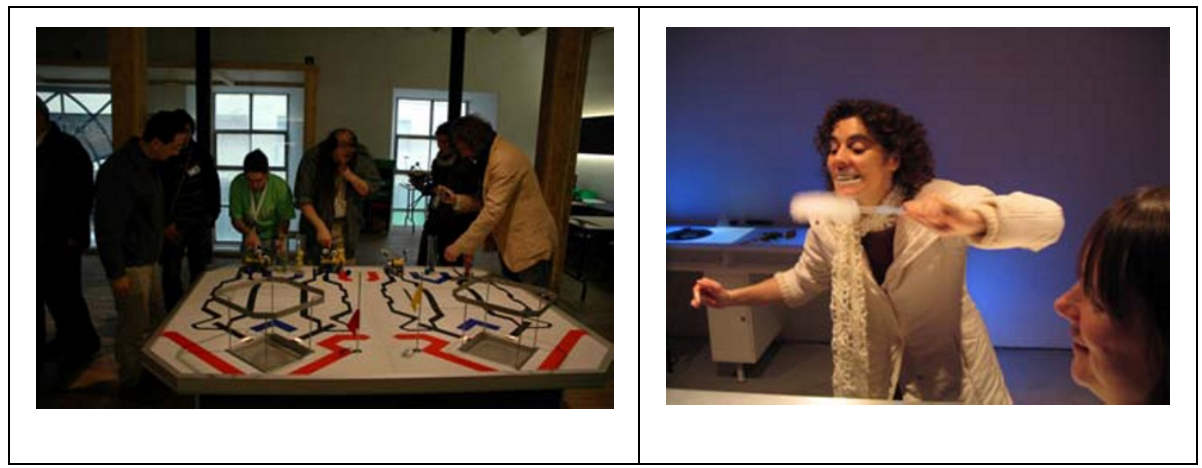

Fig. 1. Racing the LEGO robots along the tracks

Fig. 2. Trying out the home-made "toothpaste"

The theme of HCIEd 2007 was Creativity ${ }^{3}$ : Experiencing to Educate and Design seeking to encourage participants to think about the need for both creative teaching and also teaching for creativity. While it has been argued that creativity is an innate human quality, it is also true that expanding our experiences of creativity and increasing our repertoire of design solutions can substantially improve our ability to develop innovative HCI design solutions.

Creativity, education and design are big issues. The goal of HCIEd 2007 was to explore and extend the reach of these concepts in HCI education, focusing on the creation of vivid and compelling learning experiences. It sought to forge a better understanding of creative processes and abilities and to nurture creative, freethinking mindsets.

As befits a conference focused on creativity, the conference format encouraged creative thinking, from carefully chosen pens and conference bags, to playing with LEGO robots and making toothpaste during a visit to Fábrica da Ciência (http://www.ua.pt/fabrica/), a hands-on science museum (Fig. 1 and 2). (Even the conference dinner broke new ground featuring a live demonstration of cooking as a design activity. A professional cook, a macrobiotic cook and a house wife (Fig. 3) were given identical ingredients and were asked to prepare the participants' desserts during the main course of dinner. Some of the results can be seen in Fig. 4. Whilst the ingredients were exactly the same, the results were as different as can be, just as in any design process! 


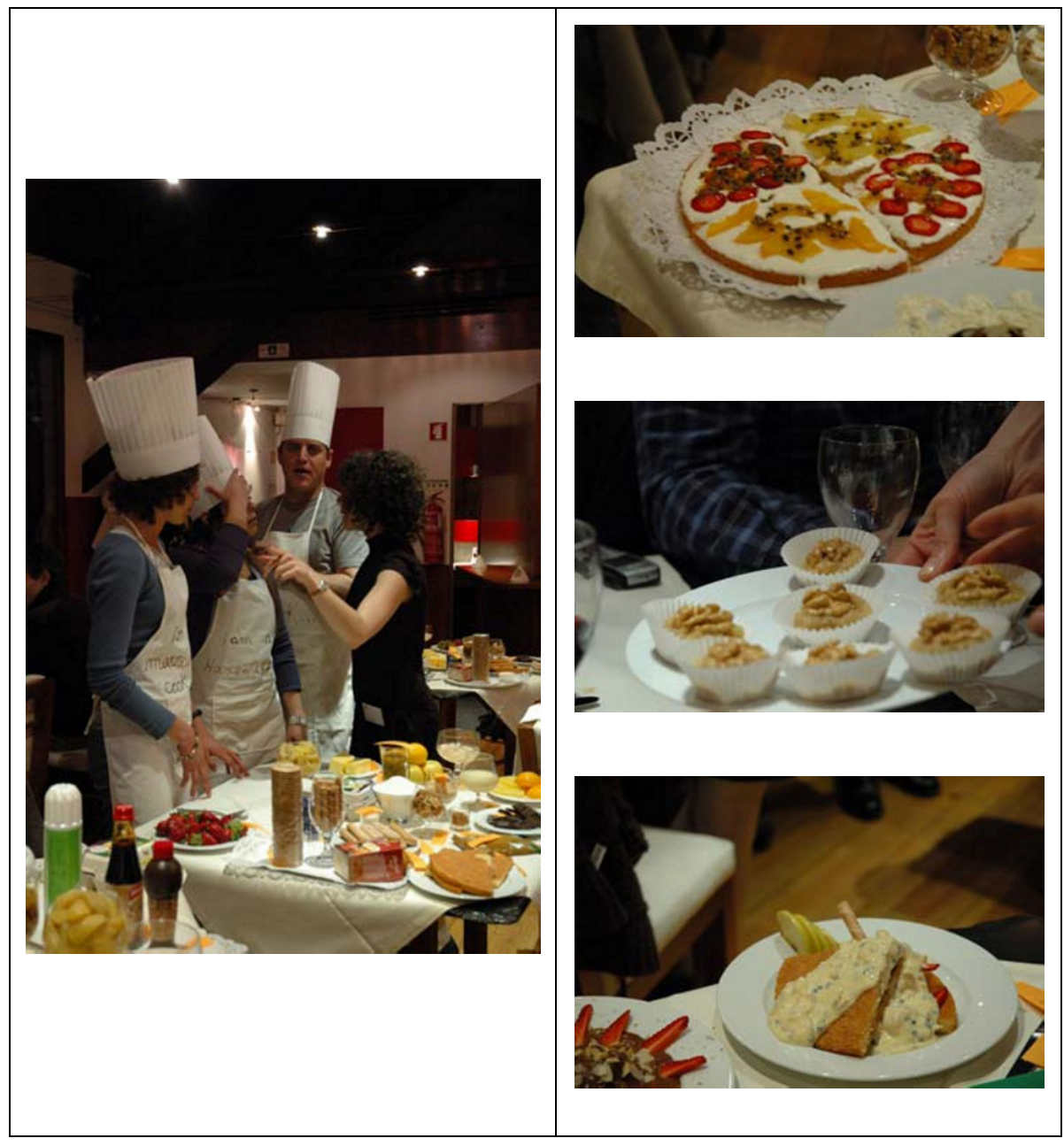

Fig. 3. The chefs - upon learning of their task

Fig. 4. The variety of desserts (design solutions) that emerged from the same ingredients

This is not mere frivolity. To address novel and changing environments, user needs and technology, we need our students to think and act innovatively and creatively. However, to teach innovation and creativity, we need innovative and creative methods, and it would be foolish to think that we can develop and reflect upon such practices if we do not create for ourselves environments and activities stimulating creativity.

The papers in this volume in various ways grapple with these issues: how we can encourage creativity, how we can promote rich design and how we can apply this not just to the mechanics, but also to the experience of interaction. In themselves they 
certainly exhibit this creativity both in addressing new aspects of HCI education and also in interrogating more traditional themes in new ways.

\section{Design and Trans/Multi Disciplinarity}

Design was one of the HCIEd 2007 themes and art of a broader agenda of transdisciplinarity. A number of papers in this volume deal with the meeting of technology design as encountered (largely) in computing science backgrounds and other forms of more aesthetic-focused design practices such as industrial design, graphic design and architecture, whilst some stretch further still and seek to include inspiration from cinematography, arts and crafts (van der Veer [4]) and even placing HCI within widening spheres that eventually lead to the 'meta-disciplines' of philosophy, art, mathematics and science (Bongers and van der Veer [5]).

The word 'design' is perhaps becoming increasingly problematic. In software engineering 'design' is one the standard stages meaning the 'design' of code to meet an objective, in HCI 'design' is also a common stage referring to the more behavioural aspects influencing the user ... itself part of the broader process of interaction design. However, increasingly when we say 'design' or 'designer' in HCI the image is of mainly industrial/graphic design or possibly experience design.

Give this caveat, several authors have embedded elements of 'design' (meaning industrial/graphic) practice within a computing syllabus including Greenberg [6], who describes the user of various practices as part of a studio-based approach including the use of sketch books (drawing on Buxton's inspiration [7]); and Kotzé and Purgathofer [8], who use components of good design garnered form several sources.

In contrast Leblanc [9] comes from an environmental design context and has been seeking ways to instil trans-disciplinary thinking in her students. Rather than adopting a syncretistic approach, instead multidisciplinary teams were encouraged to establish a common knowledgebase while addressing real-life problems, and given the intellectual means to do this by short intensive block of different disciplines, but focused around a common topic. The power of concrete examples or problems to enable cross-disciplinary thinking is a theme that can be found from project-focused work in primary schools to scenario-based approaches in research projects. The eschewing of a simplistic homologisation of disciplines is perhaps pertinent for more specialised HCI courses where we may risk loosing deeper disciplinary understanding.

In HCI, while we embrace the strengths and lessons to be learnt from other disciplines, it is important to note the strengths that have emerged in our own area over the last 25 years, that we must both hold on to ourselves and offer to others. In particular, Kotzé and Purgathofer [8] remind us that the user and human focus, which we take for granted in HCI, is rare both in other areas of computer science, and also in most traditional 'design'. Within design teams both technological and aesthetic, our students need to be prepared to stand up for utility and fitness for purpose rather than conceptual purity and delighting the end-users or impressing the design community. We have much to learn, but also much to give. 
While the authors in this book and most likely you, the reader, may take the value of cross-disciplinary work for granted, this is often not the case within the broader disciplinary areas within which we work, and van der Veer's [4] account of the end of their innovative course underlines the political fragility of crossdisciplinary work within many academic institutions.

\section{Creativity, Constraints and Problem Solving}

As already noted, creativity was a hot topic at HCIEd 2007 and amongst the papers in this volume. In their report on HCIEd 2006 in Limerick, Wong et al. list a number of questions addressed by the papers in that conference. This included:

- 'Nature vs. nurture: can creative invention be taught?'

- 'What tools and methods are there to help students learn to develop creative solutions?'

Many of the papers in this volume address these issues offering explicit ways to teach and support creativity and innovation.

A common problem is that students (and indeed designers) are blinkered by standard solutions to problems rather than finding novel ones, or become personally committed to early designs; Larusdottir [10] describes her students getting 'locked' into designs at prototype stage.

To avoid this, various authors force their students into novel or unfamiliar situations. Greenberg [6] poses design briefs for his students in a 'personally unfamiliar interaction area'; Oestreicher [11] uses challenging examples of bad design ('mind shakers') to stimulate students to 'break away from traditional ways of thinking'; Bongers and van der Veer [5] have students design for unusual application areas including a musical glove and 'interactive architectural forms'; and Sas and Dix [12] use unusual technology to prompt students to explore new application areas.

Paradoxically, while creativity is often about breaking bounds, also much of the literature on creativity emphasises the importance of various forms of constraint. Not surprisingly this also figures in many of the papers in this volume. Oestreicher [11] mentions the importance of a 'constrained design space' and how 'restraining can force the students into lateral thinking'; this is implicit also in many of the design briefs used by other authors. Sas and Dix [12] not only constrain the technology, but also encourage students to explicitly explore the nature of the constraints imposed by the technology. Even during the mundane task of note taking, Read et al. [13] report on constraining students to three electronic worksheets in order to prevent unlimited scribbled notes. In contrast, Greenberg [6] has (verbally) reported that he forces his students to produce 10 initial ideas in order to avoid early fixation ... different kinds of constraint are important at different stages of education and design.

As well as constraints on the design itself, often creativity is encouraged by quite structured process. We see this in many papers including Greenberg's [6] structured studio sessions and Leblanc's [9] structured ideation/creativity sessions that make use of linguistically inspired techniques, categorisation and scenarios. These structured creativity techniques are themselves often inspired by theoretical 
understanding of creativity. For example, Kotzé and Purgathofer [8] use Laseau's twin funnels [14] of elaboration and reduction to structure their understanding of the role of techniques such as sketches and prototypes; Wesson [15] draw on various techniques such as BadIdeas [16]; Rapid Contextual Design [17]; and Beckhaus' seven factors to support teaching creative design [18]; and Sas and Dix [12] use an explicit representation of the design space to explicate the way their technologyfocused brief encourages innovation.

These theoretical understandings are important as they help protect us from oversimplistic and dualistic characterisations of creativity: right brain vs. left brain, divergent vs. convergent, open vs. structured. In Csikszentmihalyi's [2] studies of 'creative' people, one of the observations was that many of them were extreme on many of the scales of personality and cognitive type ... but it was not because that they were all on one extreme, nor even that different individuals were on different extremes, but that single individuals, exhibited both extremes. As educators it is not so much that we want to take all those over-focused computer scientists and teach them to be more open-minded like arts students, but that we want to show them how to think divergently without losing structured attention, and to teach those with more divergent minds also to apply more analytic methods.

\section{Education, Assessment and Evaluation}

Of course the whole of this volume is about HCI education, so not surprisingly there are interesting lessons for general HCI education beyond those specifically about creativity or trans-disciplinarity.

Several papers mention that HCI is still seen as somehow 'soft' or 'woolly' by both students and fellow staff (e.g. Read et al. [13]) even though students are 'not always very successful at mastering it' (Chambel et al. [19]). We still clearly have a big education job here not just teaching techniques, but educating about HCI itself to our students and colleagues. It is interesting to note that several paper present examples of their best student work (e.g. Bongers and van der Veer [5] and Fonseca et al. [20]), and of course we want to show how good students can be when taught effectively. Oestreicher's [11] use of bad examples to motivate students is one approach to educating students, but perhaps also we ought to collect bad examples of our students work in order to say 'yes you do have something to learn' ... and maybe we should collect examples of systems our colleagues produce!

As with the teaching of creativity, theoretical approaches were evident, for example, Oestreicher [11] reviews several models including Bloom's taxonomy [21] and the 'Pyramid of Competence' [22], both of which emphasise higher level understanding and application of knowledge leading to meta-cognitive skills, not just mere rote learning. Fonseca et al.'s [20] focus on conceptual design also picks up this need for reflective application for both good interaction design and creative design. Another high-level skill is the need for clear problem framing, an issue raised by Leblanc [9] quoting Csikszentmihalyi [2] 'how you define a problem usually carries with it an explanation of what caused it', but is implicit in several others. However, worryingly Larusdottir [10] found that $73 \%$ of students reported they did 
not understand the requirements fully when they were half way through their project period. At best, this may simply reflect the fact that usability requirements often only become clear as we engineer solutions ... but probably also means that we have some way to go in teaching students how to understand problems.

While we all recognise the importance of teaching students about accessibility, Chambel et al. [19] raised the issue of accessibility of our teaching - how do you teach blind students. In fact there are several practicing usability professionals and academics who are blind and yet have not only learnt HCI, but teach it as well. This issue also affected the work reported by Read et al. [13] in that the CRaSH system could not be deployed more widely because it was too visual and therefore did not meet accessibility standards within the institution. With, very welcome, accessibility legislation in many countries, this may become an increasing issue for any form of practice-based user-interface research where even early prototypes may need to be designed to full accessibility standards if they are to be used in deployed, albeit experimental, applications.

Issues of collaboration and sharing are mentioned in several papers. Group based projects are common and Larusdottir [10] found that project and team management were one of the crucial success factors for student projects. As well as collaboration with groups or teams, more general sharing is often encouraged: Read et al.'s [13] CRaSH system is explicitly built to facilitate on this, and Greenberg [6] seeks to encourage 'ideas exchange' even though 'conventional courses call this cheating'. The latter also reminds us again of disciplinary conflicts and also problems of assessment ... how do we design project work that is both meaningful, and also assessable!

Assessment is particularly difficult for creativity or innovation. Wesson [15] uses a variant of 'functional creativity' (borrowed from the engineering domain) assessing whether the product produced exhibits novelty (is it original or innovative), relevance and effectiveness (does it do what it is supposed to do) and is germinal (does it lead to new metaphors and/or designs). Assessing these aspects is still bound to be very subjective and Greenberg [6] in his talk at HCIEd 2007 said that his criterion for an ' $A$ ' grade was if the work 'knocked his socks off'!

Koukouletsos et al.'s [23] paper is rare in that it reports a rigorous comparative study of techniques for teaching usability: patterns vs. guidelines. The complexity of usability and the complexity of learning mean that theoretical understanding, shared personal experiences and hard empirical evidence are all needed. However, evaluation of education is fraught with methodological problems, not least for metacognitive skills such as creativity, where one would argue that the true value lies in long-term change of mindset, not necessarily short-term outcomes. It is hard enough to assess the creativity of a single product or process; how are we to assess the success of education for creativity?

\section{Experience and Change}

As described previously, the HCI Educators conference in Aveiro was an Experience (capital intentional!). We all know that user experience has become an important 
issue of what we teach in HCI and throughout this volume there are instances that indicate the importance of experience in learning about HCI. Kotzé and Purgathofer [8] say that 'students must experience design to enable them to learn effectively' and Leblanc [9] talk about the importance of students being immersed in each discipline they study. Education is experience design!

However, what constitutes a good 'experience' is maybe itself changing. Van der Veer [4] notes that users of the iPod 'enjoy uncertainty', and it is perhaps notable that while the complexity of the web has grown, the 'lost in hyperspace' issues that dominated hypertext and early web usability is now forgotten - not forgotten because it has been solved, but forgotten because nobody cares anymore. Is this simply cyber-culture or a deeper cognitive shift? On television programmes the average length of shots has halved in the last 15 years - do our professional practices need to change as the 30 second attention span generation grows up and becomes our students and the designers of tomorrow?

Van de Veer also paints a picture of change users who are increasingly savvy in the use of technology but ignorant of its mechanisms. This may point the way to better metaphors and designs to enable users to make sense of increasingly complex functionality, or may mean we have to increasingly design more 'intelligent' interfaces that do the right things for users even if the users have no idea how they behave ... an 'I'm feeling lucky' button on your car's satellite navigation system?

Whichever way the future moves, it is clear that our students need more than a set of rules optimised for 1980s GUIs or even 2008 smart phones. Instead they need the means to adapt and change to a changing world, to be deeply versed on the fundamentals of human behaviour and technical possibilities, but also ready to invent, innovate and create. And our job is to prepare them for that.

\section{References}

1. J. Nielsen, Useit.com: Jakob Nielsen's Website, (cited 10 May 2008); http://www.useit.com/ (Nielsen Norman Group, Fremont, 2008).

2. M. Csikszentmihalyi, Creativity, Flow and the Psychology of Discovery and Invention (HarperCollins Publishers Inc., 1997).

3. W. Wong, P. Kotzé, J. Read, L. Bannon, and E. Hvannberg, From inventivity in Limerick to creativity in Aveiro: Lessons learnt, in: Creativity and HCI: From Experience to Design in Education - Selected Contributions from HCIEd 2007 (this book), edited by P. Kotzé, W. Wong, J. Jorge, A. Dix, and P.A. Silva, IFIP Series, (Springer, 2008), pp. 19-29.

4. G.C. van der Veer, Between the ivory tower and babylon-Teaching interaction design in the 21st century, in: Creativity and HCI: From Experience to Design in Education Selected Contributions from HCIEd 2007 (this book), edited by P. Kotzé, W. Wong, J. Jorge, A. Dix, and P.A. Silva, IFIP Series, (Springer, 2008), pp. 150-165.

5. B. Bongers and G. van der Veer, HCI and design research education, in: Creativity and HCI: From Experience to Design in Education - Selected Contributions from HCIEd 2007 (this book), edited by P. Kotzé, W. Wong, J. Jorge, A. Dix, and P.A. Silva, IFIP Series, (Springer, 2008), pp. 97-112. 
6. S. Greenberg, Embedding a design studio course in a conventional computer science program, in: Creativity and HCI: From Experience to Design in Education - Selected Contributions from HCIEd 2007 (this book), edited by P. Kotzé, W. Wong, J. Jorge, A. Dix, and P.A. Silva, IFIP Series, (Springer, 2008), pp. 30-46.

7. B. Buxton, Sketching User Expereinces - Getting teh Design Right and the Right Design (Morgan Kaufman, San Francisco, 2007).

8. P. Kotzé and P. Purgathofer, Designing design exercises - From theory to creativity and real-world use, in: Creativity and HCI: From Experience to Design in Education - Selected Contributions from HCIEd 2007 (this book), edited by P. Kotzé, W. Wong, J. Jorge, A. Dix, and P.A. Silva, IFIP Series, (Springer, 2008), pp. 47-66.

9. T. Leblanc, Transdisciplinary Design Approach, in: Creativity and HCI: From Experience to Design in Education - Selected Contributions from HCIEd 2007 (this book), edited by P. Kotzé, W. Wong, J. Jorge, A. Dix, and P.A. Silva, IFIP Series, (Springer, 2008), pp. 113129.

10.M.K. Larusdottir, A case study - Hindrances and success factors in student projects, in: Creativity and HCI: From Experience to Design in Education - Selected Contributions from HCIEd 2007 (this book), edited by P. Kotzé, W. Wong, J. Jorge, A. Dix, and P.A. Silva, IFIP Series, (Springer, 2008), pp. 196-209.

11.L. Oestreicher, Teaching human-computer interaction from real world examples Furnishing creativity? in: Creativity and HCI: From Experience to Design in Education Selected Contributions from HCIEd 2007 (this book), edited by P. Kotzé, W. Wong, J. Jorge, A. Dix, and P.A. Silva, IFIP Series, (Springer, 2008), pp. 67-84.

12.C. Sas and A. Dix, Enhancing creativity in interaction design: Alternative design brief, in: Creativity and HCI: From Experience to Design in Education - Selected Contributions from HCIEd 2007 (this book), edited by P. Kotzé, W. Wong, J. Jorge, A. Dix, and P.A. Silva, IFIP Series, (Springer, 2008), pp. 182-195.

13.J.C. Read, M. Horton, G. Sim, and E. Mazzone, CRaSh-ing into HCI, in: Creativity and HCI: From Experience to Design in Education - Selected Contributions from HCIEd 2007 (this book), edited by P. Kotzé, W. Wong, J. Jorge, A. Dix, and P.A. Silva, IFIP Series, (Springer, 2008), pp. 225-235.

14.P. Laseau, Graphic Thinking for Architects \& Designers (Wiley, 2000).

15.J. Wesson, Teaching creative interface design: Possibilities and pitfalls, in: Creativity and HCI: From Experience to Design in Education - Selected Contributions from HCIEd 2007 (this book), edited by P. Kotzé, W. Wong, J. Jorge, A. Dix, and P.A. Silva, IFIP Series, (Springer, 2008), pp.

16. A. Dix, T. Ormerod, M. Twidale, C. Sas, P.A.G. da Silva, and L. McKnight, Why bad ideas are a good idea, in: Inventivity: Teaching Theory, Design and innovation in HCI, Proceedings of of HCIEd2006-1 First Joint BCS/IFIP WG13.1/ICS/ EU CONVIVIO HCI Educators' Workshop, 23-24 March 2006, Limerick, Ireland, edited by E.T. Hvannberg, J.C. Read, L. Bannon, P. Kotzé, and W. Wong, (University of Limerick, Limerick, 2006), pp. 9 - 14.

17.M.K. Larusdottir, Using Rapid Contextual Design at Reykjavik University, in: Inventivity: Teaching Theory, Design and innovation in HCI, Proceedings of of HCIEd2006-1 First Joint BCS/IFIP WG13.1/ICS/ EU CONVIVIO HCI Educators' Workshop, 23-24 March 2006, Limerick, Ireland, edited by E.T. Hvannberg, J.C. Read, L. Bannon, P. Kotzé, and W. Wong, (University of Limerick, Limerick, 2006), pp. 35 -39. 
18. S. Beckhaus, Seven Factors to foster creativity in university HCI projects, in: Inventivity: Teaching Theory, Design and innovation in HCI, Proceedings of of HCIEd2006-1 First Joint BCS/IFIP WG13.1/ICS/ EU CONVIVIO HCI Educators' Workshop, 23-24 March 2006, Limerick, Ireland, edited by E.T. Hvannberg, J.C. Read, L. Bannon, P. Kotzé, and W. Wong, (University of Limerick, Limerick, 2006), pp. 91 - 95.

19. T. Chambel, P. Antunes, C. Duarte, L. Carriço, and N. Guimarães, Reflections on teaching human computer interaction to blind students, in: Creativity and HCI: From Experience to Design in Education - Selected Contributions from HCIEd 2007 (this book), edited by P. Kotzé, W. Wong, J. Jorge, A. Dix, and P.A. Silva, IFIP Series, (Springer, 2008), pp. 130149.

20.M.J. Fonseca, J.A. Jorge, M.R. Gomes, D. Gonçalves, and M. Vala, Conceptual design and prototyping to explore creativity, in: Creativity and HCI: From Experience to Design in Education - Selected Contributions from HCIEd 2007 (this book), edited by P. Kotzé, W. Wong, J. Jorge, A. Dix, and P.A. Silva, IFIP Series, (Springer, 2008), pp. 210-224.

21.K. Baumann, Design education methods - Examples and findings in: Proceedings CONVIVIO Faculty Forum: Teaching Design for HCI (Graz, Austria, CONVIVIO, 2006).

22.P. Kotzé, K. Renaud, and J. Van Biljon, Don't do this. Pitfalls in using anti-patterns in teaching human-computer interaction principles, Computer \& Education, 50, 979 - 1008 (2008).

23.K. Koukouletsos, B. Khazaei, A. Dearden, and M. Ozcan, Teaching usability principles with patterns and guidelines, in: Creativity and HCI: From Experience to Design in Education - Selected Contributions from HCIEd 2007 (this book), edited by P. Kotzé, W. Wong, J. Jorge, A. Dix, and P.A. Silva, IFIP Series, (Springer, 2008), pp. 166-181. 